\title{
La disposición del cuerpo sin vida en la instancia ritual del velatorio
}

\author{
Dolors García Torra
}




\section{Abstract}

The change of the situation - from being alive to being dead - is ensured by the funeral ceremony. The presence of the dead body in the wake, in the Igualada funeral parlor, enables a staging in which some actors give meaning to it through dramatic events making the sociability of transit, turning the corpse into a deceased. An interactive process scheduled for mourners and culturally organized according to rules set by tradition, within a limited time and space, with the peculiarity that it will not be discussed from the front, face to face with the public, but from behind, where the lifeless body is arranged.

\section{Key words:}

the presence of the body, wake, front, backstage, funeral ritual. 


\section{Resumen}

El cambio de situación - pasar de estar vivo a estar muerto- se asegura mediante la ceremonia funeraria. La presencia del cuerpo sin vida en la instancia ritual del velatorio, en el tanatorio de Igualada, posibilita una puesta en escena en la cual unos actores le dan sentido mediante unos actos dramáticos que marcan la sociabilidad del tránsito, convirtiendo el cadáver en difunto. Es un proceso interactivo, pautado por los asistentes al funeral y organizado culturalmente según unas reglas fijadas por la tradición, en un espacio y un tiempo limitados, con la peculiaridad de que no se analizará desde la parte de delante, de cara al público, sino por detrás: en el lugar en el cual se adecenta el cadáver.

\section{Palabras clave:}

cuerpo presente, velatorio, front, backstage, ritual funerario. 


\section{Introducción}

Procurar un buen morir, en el hospital, teóricamente asegura que las personas no suframos en los últimos días de nuestra vida. En una relación interpersonal con el paciente, médico y familia le proporcionan medidas de confort y se controla el dolor en su fase como moribundo, en la que no puede comprender ni controlar la situación por sí mismo. Como un aparato de monitorización de constantes vitales, pero humano, observando el mínimo gesto o señal que emita, las atenciones al moribundo se llevan a término con suma precisión. Los cuidados post mortem vienen a continuación, una vez superada la fase de agonía, cuando el enfermo ha muerto y los familiares se han retirado de la habitación. La preparación de lo que será la ceremonia del cuerpo presente en la instancia ritual del velatorio se inicia entonces, prestando los últimos cuidados de enfermería para su traslado a la morgue y su posterior derivación a otros profesionales, concretamente a los profesionales de la muerte del tanatorio de Igualada —allí se centró el trabajo de campo-, para que continuaran las tareas de atenciones y cuidados iniciadas en el contexto de la asistencia sanitaria, pero esta vez al cadáver, tan dependiente como en la fase de moribundo, cuando aún respiraba, al que procuran la última asistencia, antes de enterrarlo.

\section{Metodología}

El presente artículo analiza los resultados de una investigación cualitativa basada en la observación participante, en particular la observación del «pequeño mundo» del trabajo profesional en torno a la muerte, la mayoría de cuyas operaciones se ejecutan fuera de la vista de los no profesionales. El conocimiento de la industria funeraria, como apunta Mary Bradbury, no es general. No sabemos lo que hacen los tanatoprácticos, los embalsamadores ni los médicos forenses: más bien se nos oculta su trabajo. Por este motivo, investigar dentro de estos campos requiere familiarizarse con los lugares, las escenas, las conversaciones, etcétera (Bradbury, 1999, p. 203). Escoger el tanatorio de Igualada para observar y analizar las actividades del arreglo del cuerpo sin vida respondía, precisamente, a buscar un lugar reducido que nos fuera de entrada de confianza y, de esta forma, garantizar esta familiaridad y cotidianidad que Bradbury (1999) aconseja para observar el tratamiento «técnico» del muerto y de la muerte. 
En el tanatorio de Igualada se atiende un volumen de difuntos considerablemente más reducido que en un tanatorio como el de Sancho de Ávila de Barcelona, un lugar que al principio tuvimos en cuenta como posible unidad de observación, pero una atención sistemática, como la que hemos desarrollado a lo largo de la investigación, no habría sido posible en un lugar donde el tratamiento de los restos se divide en diferentes equipos de trabajo, especializados únicamente en la secuencia concreta que se les ha delegado. En cambio, en la empresa Funeraria Anoia, la muerte es personalizada y el tanatorio presenta los elementos para hacer el tránsito lo más cómodo y confortable posible. A la vez, permite un contexto familiar de recogimiento y momentos íntimos con la muerte y de relación cercana con sus trabajadores, conocidos por gran parte de los habitantes de Igualada. En otras palabras, la presencia o la ausencia de símbolos que impregna el ritual de cuerpo presente se puede observar más nítida y sistemáticamente en un lugar menos industrializado, como el tanatorio de Igualada.

Como resultado del trabajo sistemático de observación, la investigación aporta testimonios etnográficos sobre las actividades de disposición del cuerpo sin vida, en una coordinación entre dos espacios —el público y el privado - necesarios e imprescindibles para la significación de la muerte y de la pérdida. Su originalidad consiste en abordar esta cuestión desde una perspectiva posicional poco habitual, como es la que atiende las prácticas y los discursos mortuorios sobre todo desde su parte posterior y menos visible: el trascenio, donde se lleva a cabo el tratamiento del cuerpo del difunto inmediatamente antes de su presentación en público como actor principal de su último adiós.

El acceso al campo fue fácil. Conocíamos a los actuales propietarios de la funeraria y en seguida contactamos con ellos. Tras exponerles nuestro proyecto, que fue aprobado, en ningún momento nos pusieron impedimentos a la tarea de observación, que llevamos a término por todo el recinto. El único límite impuesto fue la no intrusión en la sala del velatorio cuando el cuerpo y los familiares estuviesen presentes, a fin de mantener el respeto a la privacidad. Además, tuvimos el privilegio de encontrar a unos informantes cualificados, expertos en el tema y con una experiencia dilatada en la profesión de la muerte, a quienes no les importaba que los acompañásemos todo el tiempo en sus rutinas diarias, mientras nos explicaban en detalle todas las actividades que realizan en su jornada de trabajo. 
Nuestra situación en el terreno fue de implicación personal e incluso, en momentos puntuales, participamos en las tareas como unos trabajadores más. De esta forma, el hecho inevitable de establecer vínculos prácticos y emocionales con nuestros informantes nos permitió obtener los datos directamente de descripciones verbales extraídas de conversaciones causales registradas en el diario de campo. La misma inercia y habilidad con la que hacen su trabajo se transmitía en sus respuestas. Otras fuentes de datos fueron entrevistas en profundidad al personal de la funeraria, formularios burocráticos, hojas de servicio y las normativas de los servicios funerarios y de la policía sanitaria mortuoria. También se recogieron datos de la observación de las salidas de la iglesia de los asistentes al funeral tras la celebración de la misa y de entierros en diferentes cementerios.

El trabajo de campo se ha desarrollado en dos etapas. La primera ha consistido en la presencia asidua en las ceremonias fúnebres celebradas en el tanatorio, donde se observó la interacción social que se da en las instancias más públicas, la que se genera en las tareas de recepción y acomodación de los asistentes al funeral y en la celebración de misas exequiales en el mismo edificio. En la segunda etapa, el espacio de observación se desplazó a las estancias separadas de la percepción del público, donde se llevan a cabo las labores de recogida de cadáveres, acondicionamientos tanatoprácticos y preparación de túmulos y féretros. De esta forma, en un entrar y salir constantes entre un espacio y otro - el público y el privado- pudimos verificar los numerosos momentos de sociabilidad que se dan durante la escenificación del final de la vida, no solo a la vista de los participantes, sino también detrás, en el lugar donde el personal funerario atiende al cadáver para su posterior exhibición en el velatorio.

Para la observación y el análisis concreto del significado del ritual del acondicionamiento del cadáver en las sociedades occidentales actuales nos centramos en las prácticas alrededor del final de la vida, no pensando tanto en la muerte sino en su ritualización. Para este quehacer, los supuestos del interaccionismo simbólico, concretamente el enfoque dramatúrgico de Erving Goffman, a partir de los cuales la vida es como un teatro en tanto que consiste en actuaciones (performances) en las cuales hay actores y público, me ayudaron a ordenar los datos resultantes de la observación del ritual de interacción que se da en la realidad social comprendida en la ceremonia funeraria de cuerpo presente, una situación en la cual el cadáver moviliza el drama y la exhibición pública del finado expresa un encuentro en un espacio formalizado en el cual se desarrolla una conducta expresiva. En esta puesta en escena, la considerable sociabilidad a la vista del cuerpo y las normas de higiene sanitaria dictan 
la preparación del cadáver en vías de putrefacción. Patrones establecidos con la familia inmediata, como «Que se vea bien», insinúan que durante el velatorio y el entierro el difunto es venerado en su cuerpo, un hecho que requiere prácticas de tanatopraxia para darle el aspecto de una persona que duerme y para conservar una imagen decorosa, compatible con su veneración. Para conseguirlo, los profesionales de la muerte se implican en su presentación: una accesibilidad ritual que regulan mediante técnicas diversas de control de la impresión que produce el finado y, al mismo tiempo, penetrar en la impresión de los dolidos para captar sus verdaderos sentimientos e intenciones. Con unos movimientos aparentemente simples de entrar y salir en escena y de control de los canales de comunicación entre el cadáver y los presentes en el ritual, todo está listo para que la muerte transcurra sin ningún contratiempo.

\section{Resultados}

\section{El cuerpo presente}

En su clásico, Robert Hertz, en lo que presentaba como sociedades primitivas, no contaminadas por la presencia de extranjeros, la muerte no siempre se presenta ni se siente como entre nosotros. Por ejemplo, para los dayak de Borneo, el ritual funerario comprendía entre siete meses y un año. Durante este tiempo, depositaban provisionalmente el cadáver en un lugar aislado del resto de la comunidad, en espera de las segundas exequias. Esta larga exposición provisional del cadáver requería un velatorio permanente, que servia para preparar el cuerpo del difunto antes de ser transportado a su última sepultura y así, una vez recibidos los cuidados obligatorios por parte de los vivos, integrarse plenamente en el mundo de los muertos (Hertz, 1990, p. 35-42). La larga espera del finado, que por lo general respondía a la necesidad de exorcizar el cadáver de las malas influencias de los espíritus, corresponde a lo que Arnold Van Gennep, en su obra Los ritos de paso (1985), denomina «fase liminal o lindar» de un rito de paso. Mediante tres fases o períodos a través de los cuales un individuo transita entre funciones y roles sociales - separación, margen o liminaridad e integración-, el exitus humano como tránsito entre puntos de la estructura social es protocolizado para asegurar la integración del muerto en el lugar previsto para él en el orden societario o el punto preestablecido en el organigrama social: la comunidad de los muertos. Durante la celebración mortuoria es separado de la comunidad de los vivientes y permanece en un estado de limbo por un tiempo, antes de «renacer» como antepasado, espíritu o fantasma. 
En los rituales funerarios, la fase liminal del pasaje del estado de vivo a muerto corresponde a la exhibición pública del cuerpo del finado y al tratamiento del cadáver.

La muerte, suprema certeza de la biología, siempre nos deja un cadáver, concreto y real, que sufre profundas transformaciones orgánicas. Desde las sociedades tradicionales hasta las sociedades tecnificadas y científicas como la nuestra, el término «cadáver» ha sido el símbolo de la putrefacción y la impureza por excelencia. «A causa de esto y de otras fantasías que gravitan alrededor del cuerpo sin vida, todas las culturas se esfuerzan para componerlo, con la finalidad de superar el horror de su inminente transformación y destrucción orgánica» (Thomas, 1989, p. 109), excepto algunas que prefieren su descomposición, para la posterior ingestión de sus cenizas después de ser incinerado, como los yanomami del estado de Amazonas, en Venezuela. Aun así, en muchos casos el cuerpo inerte nunca ha sido considerado un simple envoltorio biológico. Conectado a la filogenética del ser humano, son restos de humanidad y no meros residuos orgánicos (Favole, 2003, p. 22) y por eso la tanatomorfosis contundente que el cuerpo protagoniza entre el estado de agonía y la reducción última a polvo es uno de los espacios de mayor significación para individuos y colectividades, generador de representaciones y prácticas procesadas a partir de sistemas y complejas creencias.

El adiós al finado en los rituales funerarios con la interposición del cadáver es, parafraseando a Thomas (1991), una «retención del difunto» o una reapropiación temporal del cuerpo, que es entonces el eje central de atenciones culturales. Mediante una serie de procedimientos encaminados a la gestión de los despojos del difunto que engloban las técnicas de embalsamamiento, tanatopraxia, incineración e inhumación, los restos son evacuados, cumpliéndose así la función técnica de separar el cadáver de los vivos y de instalarlo efectiva y simbólicamente en el recuerdo.

En concreto, la tanatopraxia, como conjunto de métodos que se aplican tanto para su conservación como para el soporte de su presentación a los deudos, no hace más que emprender el principio del deber tradicional de los cuidados a los muertos, que es el de preservar el cuerpo del difunto y ocultar a los vivos su putrefacción (Ariès, 1982, p. 117).

Las conductas funerarias y las ceremonias que la sociedad celebra alrededor de estos procedimientos, a pesar de su disparidad en el tiempo, obedecen a constantes universales con una doble finalidad: por un lado, no solo asignan al muerto un lugar, sino que también preservan el equilibrio individual y social de la comunidad de los sobrevivientes; por otro lado, 
la escenografía tradicional de la exposición pública del cadáver marca la irrupción de la muerte en el deseo de rendir homenaje al difunto y el baño mortuorio y la vestimenta para la correcta presentación establecen una última relación con él antes de partir al más allá. Los actos siguientes del velatorio - el entierro, las visitas frecuentes al cementerio, las oraciones por las almas del purgatorio y el duelo- son un conjunto de prácticas que demuestran respeto y afección. Este carácter estructurante y performativo de los cuerpos muertos requiere un espacio escénico - la sala de velatorio, el oratorio o la iglesia y el cementerio- y unos actores que le den sentido a través de un proceso interactivo organizado y pautado culturalmente que permita la expresión de sentimientos de dolor por la ausencia del ser querido. Los símbolos de duelo y los actos de homenaje que se representan aquí otorgan al ritual de separación «la función de socializar la pérdida, hacerla pública y participativa a la comunidad» (Allué, 1998, p. 72). Ahora bien, si en las sociedades tradicionales los «vivos se sienten intercesores de los difuntos, haciéndose patente la costumbre de no dejar solo al cadáver desde su muerte hasta el entierro, con el fin de procurar que su alma vagabunda no aparezca para atormentarlos» (Douglas, 1991, p. 85), en nuestra cultura el cuidado a los muertos pasa totalmente a las instituciones dotadas de personal especializado - tanatoprácticos-, con lo cual la ritualización de la muerte se convierte en un protocolo técnico en manos ajenas.

\section{La muerte y el muerto}

Como nos hace notar Van Gennep (2008), el individuo muerto, al separarse del grupo de los sobrevivientes, entra en un periodo de transición del que tiene que salir para incorporarse a su destino final o post mortem. Entretanto, la liminaridad que sufre el difunto en nuestra sociedad en la mayoría de los casos tiene lugar en el tanatorio o edificio donde se depositan los cadáveres durante las horas que preceden a su inhumación o cremación. La puesta en escena que aquí se representa — velatorio y ceremonia final— responde al deseo de rendir homenaje al ser querido, «habilitando un medio de entrampar la muerte en un lugar restringido al margen de la vida» (Thomas, 1991, p. 117), un lugar en el cual, mediante procedimientos científicos y eficaces que, a pesar de los progresos en términos de tratamiento sanitario de la materia muerta, continúan manifestando los símbolos que los definen y estructuran, se guía, se prepara y se dispone al difunto para su incorporación a la comunidad de los muertos. 
Este tratamiento solemne y trascendente nos remite a un cuerpo presente como objeto sagrado en el sentido canónico durkheimiano, separado y objeto de una etiqueta, unas condiciones que obligan a quienes lo reconocen a tenerle una consideración especial y un tipo de comportamiento determinado. Es lo que Radcliffe-Brown (1986) llama «valor ritual», en la medida en la que el trato que ha de recibir tiene que ser singular y sometido a determinados protocolos, justamente para hacer identificable su valor social. Un ejemplo revelador de la vigencia de este tratamiento especial es que, según el artículo 526 del Código Penal, constituye delito la profanación de un cadáver o de sus cenizas, además de una falta de respeto a la memoria de los difuntos. El ritual funerario como unidad simbólica de representación viene dado, precisamente, por la condición sagrada del finado y la puesta en escena se organiza en actos que responden al proceso de transformación de viviente a difunto, para, por último, lograr ser antepasado: un proceso ritual, cuya plusvalía es consecuencia de su estado liminal. Esta concepción procesual de la muerte en la cual el cadáver, por el ritual funerario, es sustituido simbólicamente por un cuerpo marca la socialización de una de las transiciones más importantes de la vida, un proceso interactivo pautado por actores en un espacio y un tiempo limitados. Mucho más que una masa de proteínas en vía de mineralización, el cadáver es un objeto culturalizado que tiene que mantener la imagen de cuerpo vivo más allá de la muerte, como demuestran las numerosas ceremonias de acondicionamiento del muerto. Así mismo, el hecho de presentar al difunto por última vez a los visitantes y los amigos de la manera más aceptable y agradable, conjuntamente con la ornamentación, los objetos, la música, las palabras y los gestos hacia el ser querido, «recortan un espacio donde, de manera efímera e ilusoria, el cadáver se convierte en el cuerpo que fue» (Favole, 2003, p. 67). Así, el cadáver protagonista de su tránsito se convierte en difunto a quien se atiende y, a la vez, se actúa como si estuviese vivo: «el cadáver aún está vivo, el difunto sigue lúcido (...), es preciso que todo esté normalizado para respetar su recuerdo y rendirle culto» (Thomas, 1983, p. 312).

En el tanatorio de Igualada, como en cualquier otro tanatorio, el personal funerario, una vez recibido el Certificado Médico de Defunción, realizará todas las gestiones administrativas, los trámites sanitarios y los oficios que requiere el funeral. Los cuerpos sin vida que ellos mismos recogen de las cámaras frigoríficas del hospital, las residencias geriátricas o bien en el propio domicilio familiar son trasladados y preparados para ser presentados en la sala del velatorio. La correcta presentación del cuerpo y el otorgamiento del tiempo suficiente para que amigos y parientes reciban la noticia y se acerquen son estrategias que socializan la tristeza y el dolor que produce la muerte (Panizo, 2002, p. 32). 


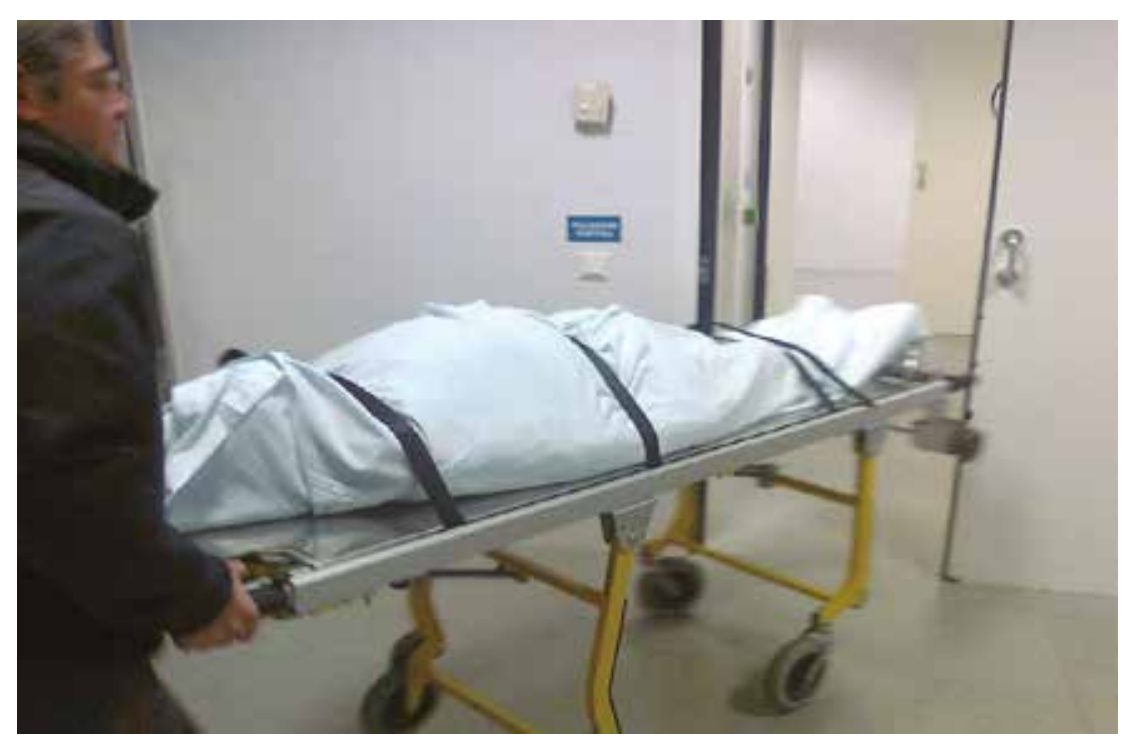

Recogida de cadáveres de la morgue. Dolors García. 2012.

Actualmente, al sustituirse la casa como lugar de acompañamiento del difunto por las salas de vela de los tanatorios y por la importancia del papel que ejerce la técnica, el ritual se ha profesionalizado: se utilizan túmulos (cámaras frigoríficas) para exponer al difunto en la sala del velatorio y el cuerpo presente se prepara y se acondiciona mediante los trabajos de tanatopraxia, de acuerdo con las normas de higiene establecidas. El corro que se solía formar en torno al lecho del moribundo para acompañarlo en su agonía, mientras lo rociaban con agua bendita —un ceremonial propio del siglo XVIII y principios del XIX en Occidente-, ha ido cayendo en desuso. La habitación del enfermo se convertía entonces en lugar público y la gente entraba libremente (Ariés, 1982, p. 25). En los tanatorios, se aparta al fallecido de la vida cotidiana para dejarlo en manos de los tanatoprácticos, quienes manipulan el cadáver y desarrollan y aplican métodos para su higienización, conservación, embalsamiento, restauración, reconstitución y cuidado estético, con la finalidad de presentarlo a sus familiares con un aspecto natural, sosegado y lo más parecido posible a la imagen que tenia en vida. La parte final del ritual funerario comprende el entierro o la incineración. El último umbral que tendrá que cruzar viene marcado por el encuentro íntimo con sus parientes en el momento de la sepultura del cuerpo o la colocación de las cenizas en la urna. Así, una vez sepultado y rotos formalmente los lazos que nos unen con nuestros difuntos, a quienes ayudamos a integrarse en el trasmundo mediante los rituales funerarios, el muerto tiene un lugar asignado y, a la vez, se preserva el equilibrio de los sobrevivientes. 


\section{Ritual e interacción social: la actuación final}

El tratamiento protocolario del finado en el tanatorio de Igualada se inicia con el acondicionamiento del cadáver y su exposición como difunto a la vista de los asistentes. Los trabajos de tanatopraxia o "presentificación», para utilizar la expresión de Payot en Thomas (1989), son controlados cuidadosamente por los trabajadores del servicio funerario. Estas labores, distribuidas en dos dependencias separadas entre sí, sin ninguna interferencia posible entre ambas - el local técnico y el local de recepción-, corresponden a la preparación de un ambiente solemne de homenaje, reunión y sociabilidad en presencia del cuerpo del difunto.

En el marco situacional del velatorio, el finado ocupa su lugar entre los otros. Como un individuo más que interacciona con los vivos - considerado aún dotado de rasgos humanos- y con la asistencia de sus ayudantes de cámara, presenta su actividad delante de los familiares y los conocidos que asisten a la ceremonia. En este contexto se reúnen también individuos invitados y admitidos de forma controlada en honor a una circunstancia valorada por todos y limitada por un estado de ánimo común. Estos llegan de manera ordenada y se colocan en el espacio acotado por las paredes del recinto para participar en la actuación de aquellos a quien han venido a ver: al muerto y a sus familiares cercanos. Con la ceremonia funeraria así dispuesta como un marco formalizado en el que se desarrolla una conducta expresiva, el difunto es el centro del ritual a quien, mediante la interacción entre el cuerpo presente, los asistentes y el personal funerario, se asigna un lugar, un espacio y un momento social. Por lo tanto, el finado como un personaje más guía y controla las impresiones que le interesa producir ante el público, con la peculiaridad de que este enfoque pertinente es calculado y controlado por los funerarios a fin de conseguir una imagen aceptable para los asistentes, que evoca la permanencia de lo que ha sido.

Nosotros hacemos lo que podemos para acondicionar el cadáver, pero a veces mueren tan mal que no sabemos qué hacerle y no lo queremos mostrar. Si la familia insiste, nosotros les avisamos. No lo hacemos por nosotros, sino que lo hacemos por ellos. (....) Nosotros procuramos que la última imagen que vean del muerto sea buena, porque es la que recordarán. Es lo que queda en la retina. No queremos que nos vean sacar el cadáver con una bolsa de PVC; lo hacemos por dignidad, no por el tanatorio. (Diario de campo 30/01/2012. Entrevista a un trabajador de la funeraria Anoia.) 
Las personas somos una cara. Si no tenemos el cuerpo, no pasa nada, pero, si nos falta la cabeza, mal. Si la familia nos dice que mi padre se peinaba la raya a la derecha y no hacia a la izquierda, se la cambiamos de lado. (Diario de campo 17/02/2012. Entrevista a un trabajador de la funeraria Anoia.)

Como recuerda Thomas, «cuidar la última imagen que el cuerpo nos ofrece y que ya no depende de él es rendirle homenaje para que pueda continuar existiendo un poco en la mirada del otro» (Thomas, 1989, p. 216). Los trabajadores de la funeraria que se encargan de procurarle al muerto una imagen y una conducta decorosa que acata la pretensión de aceptabilidad forman parte del drama como «categoría de personajes, cuya función es arreglar el escenario y proporcionar los accesorios para que los actores desarrollen su papel» (Chihu, A. y López, A., 2000, p. 251). En la sección de bastidores o backstage, el área de trabajo donde las actividades de elaboración de una representación se ocultan al público de forma estratégica, estos ayudan al actor a prepararse, utilizando los efectos especiales que se requieren para impresionar al público. Desde el punto de vista de una actuación particular, el backstage o región posterior de la representación es el lugar donde se toman todas las precauciones para salvaguardar las impresiones fomentadas por el difunto y las perturbaciones que se dan cuando estas no son las esperadas.

\section{Tampoco queremos tapar demasiado las heridas, que, por la experiencia que tenemos, sabemos que por poca cosa podemos complicar la presentación: es peor el remedio que la enfermedad. (Diario de campo 02/02/2012. Entrevista a un trabajador de la funeraria Anoia.)}

Antes de salir a escena, el actor, siempre vehiculado por los personajes descritos, sigue un circuito que le permite aparecer en cada uno de los actos: el velatorio, la ceremonia final y el entierro. En el caso del velatorio, el actor principal, una vez preparado y colocado en el féretro, es empujado con una carretilla hasta el montacargas que lo subirá al piso de arriba, delante de una puerta de la misma amplitud y altura del féretro y, al abrirla, lo hacen deslizar directamente dentro del túmulo de la sala. De esta forma, los familiares próximos, los amigos y otros convocantes a la ceremonia, al entrar se lo encuentran allí, presentado favorablemente «como una imagen digna de crédito en general» (Goffman, 2009, p. 235). Proporcionar una escena bien montada y representada requiere que el difunto regule su accesibilidad al público de acuerdo con el mantenimiento de la fachada institucionalizada y según las expectativas 
estereotipadas por la audiencia, es decir, sin mostrar el aspecto traumático de la muerte. De ahí que pueda ser retirado de la escena y recibir las atenciones desde la parte posterior, mientras la representación sigue su curso. Con precisión, los ayudantes de cámara, calculan cuándo y cómo tiene que salir a escena, manejando las impresiones públicas de manera que tengan lugar las reacciones esperadas, a la vez que se evita que se pierda el sentido de la realidad que toda ocasión social pretende.

Antes de vestirlo, por las escaleras de caracol situadas al lado del montacargas hemos subido a retirar el difunto que estaban velando en la sala seis. Durante la noche le habia salido sangre por la nariz. Sin entretenerse, han retirado el féretro del túmulo. Un olor muy fuerte impregnó la situación. Rápidamente le han cambiado el taponamiento, limpiado la cara de restos de sangre y tapado las manchas de color verdoso del cuello de la camisa y de la almohada. También le han puesto desodorante de la marca Axe, que dicen que va muy bien para disimular los malos olores. (Diario de campo 16/02/2012)

Hoy les he preguntado si podia maquillarlo. Evidentemente, lo he hecho siguiendo sus indicaciones. Me he quedado con las ganas de pintarlo y embellecerlo más. Como se trata de darle al difunto la máxima naturalidad, no quieren utilizar demasiado maquillaje, por miedo a que no parezca el mismo. Según me explican, las familias quieren que su ser querido sea lo más parecido posible a cuando estaba vivo. (Diario de campo 03/02/2012)

A la hora de maquillarla se le han perfilado los labios. Despuésle han puesto colorete. No han querido pintarle los ojos. Yo lo quería hacer, puesto que crei que no quedaba nada bien que los labios estuviesen pintados y los ojos no, pero ellos, al no tener una foto suya, preferian no hacerlo. Son prudentes. (Diario de campo 07/02/2012) 


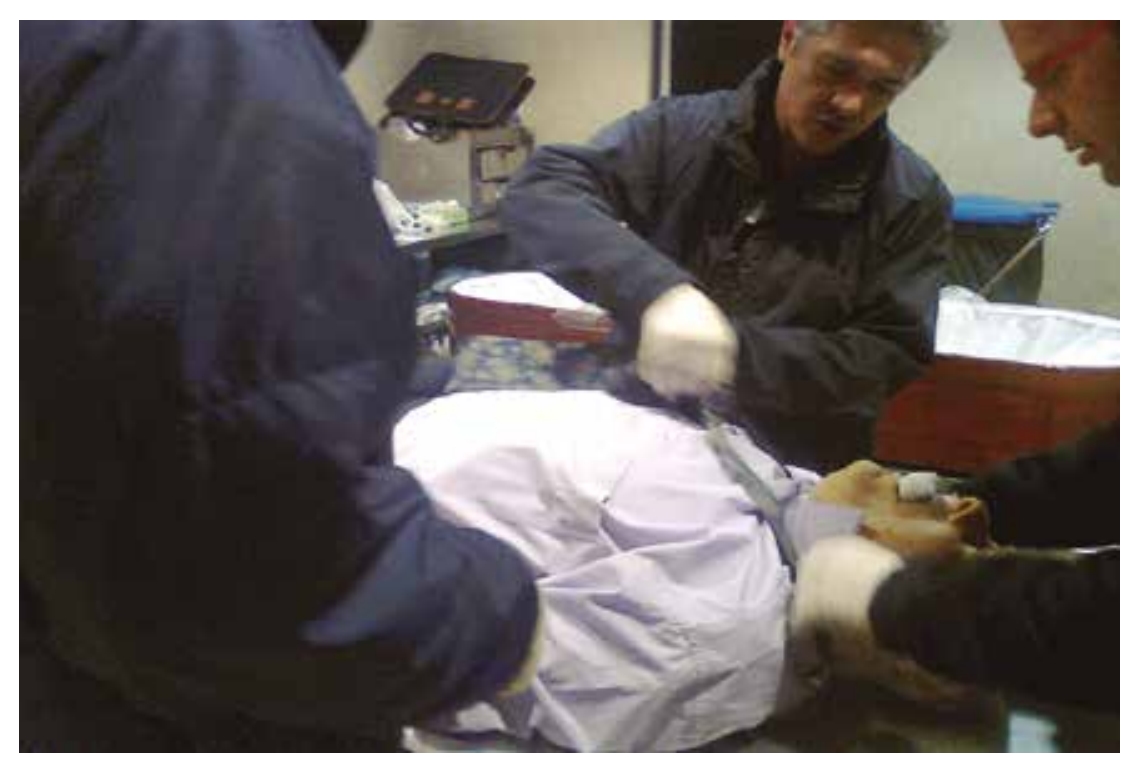

Acondicionamiento del cadáver en el backstage. Dolors García. 2012

Así mismo, Turner y Edgley, en sus investigaciones sobre los funerales en EE. UU. desde la óptica de la dramaturgia, destacan la importancia de las preparaciones del cuerpo sin vida llevadas a término en el backstage para el éxito del funeral. Las actividades que aquí desempeña el equipo —drenaje, rellenar, maquillar — se ocultan estratégicamente con el propósito de dar a los dolidos la impresión de que el ser querido se encuentra inmerso en un sueño profundo y tranquilo. Los autores también remarcan la condición de actores del director del funeral y de su equipo, cuyo trabajo es organizar una actuación conforme a lo que esperan de ellos los asistentes a la ceremonia: competencia, sinceridad, dignidad y respeto, unas expectativas que a la vez se expresan en la correcta visualización del cuerpo. Esto demuestra la importancia que atribuyen los estadounidenses al viewing of the body para el duelo posterior a la pérdida. Según los investigadores, la función más importante que se cumple al mirar el cuerpo sin vida es la confrontación del factor emocional que uno está tan ansioso de negar, pues mirar parece romper las defensas con mayor eficacia que otra parte del proceso ritual. Para ellos, la correcta apariencia sin signos de descomposición se consigue mediante la aplicación de tres técnicas - la conservación, la tanatoplastia y la tanatoestética-, cuya práctica permite la adecuación y la restauración general del cadáver, que los autores comparan con llevar a término un «arte restaurativo» (Turner y Edgley, 2005, p. 298-299). 
Manuel me enseñó el cuerpo embalsamado del rumano que llevaba quince dias muerto. Tenian que trasladarlo a su pais, pero, al final, como no se disponía del dinero para hacerlo, decidieron inhumarlo en Igualada. El cuerpo estaba duro como una piedra. La cara, el vientre, las piernas: todo. Tenia los puntos de la incisión que le hicieron para introducir la cánula por donde pasa el liquido embalsamador. Mientras me los mostraba y hablando de la preparación de los cuerpos, Manuel me explicó que un dia recibieron el cuerpo de un hombre muy estropeado al que le faltaba un ojo. Como la familia pidió ver a su padre fuera cual fuere su aspecto, para preservar la última imagen le rellenaron el ojo con una bola de silicona que lo disimulaba bastante bien. (Diario de campo 15/02/2012)

Los funerarios que llevan años trabajando en la profesión conocen muy bien los cadáveres y los manipulan con mucha facilidad. Como están acostumbrados a hacerlo, actúan con rapidez y precisión y también pueden especular sobre si sufrieron en el momento de su deceso. Las facciones muy marcadas o el empeine del pie hacia delante son, para ellos, marcas claras de sufrimiento en los últimos días de vida. Generalmente, el acondicionamiento del cuerpo exige más fuerza que destreza. El estado de rigidez post mortem dificulta su manipulación. A pesar de esto, conocen las maniobras y los puntos exactos del cuerpo que hay que presionar para que se doblen y facilitar así el trabajo de movilización.
¿Ves? Si lo coges por aqui, ella sola da la vuelta y puedes acabar de subir la falda. También tiene unos puntos, ¿̇ves?, aqui, en el codo, por ejemplo, que, si los aprietas, puedes doblar el brazo. (Diario de campo 18/02/2012. Conversación casual con un trabajador de la funeraria Anoia.)

En oposición al backstage o trasfondo escénico, las salas de velatorio, los oratorios y los cementerios son el front o fachada, los espacios físicos donde tiene lugar la representación. Los hechos que aquí se desarrollan corresponden al momento social de la muerte y a su reconocimiento público: la presentación de la persona para rendirle homenaje. El difunto, que ya ha sido vestido para la ocasión, tendido en el féretro y colocado dentro del túmulo en un sueño profundo, es la apariencia oficial prescrita, «la imagen fijada de la muerte con actitud de yaciente que espera con las manos cruzadas» (Thomas, 1983; Ariés, 1982). La sala del velatorio está preparada como corresponde para su última actuación. Los miembros afligidos del grupo familiar se disponen en ella como miembros de 
la audiencia o como un grupo de observadores, cuya función consiste en apoyar al protagonista con muestras de respeto y solidaridad. Así, el cadáver presentado en escena y con el enfoque pertinente, rodeado de quienes se han reunido para despedirlo en su traspaso a la comunidad de los muertos, se convierte en cuerpo-objeto ritual y objeto ceremonial, algo sagrado que se ha de tratar según una etiqueta determinada.

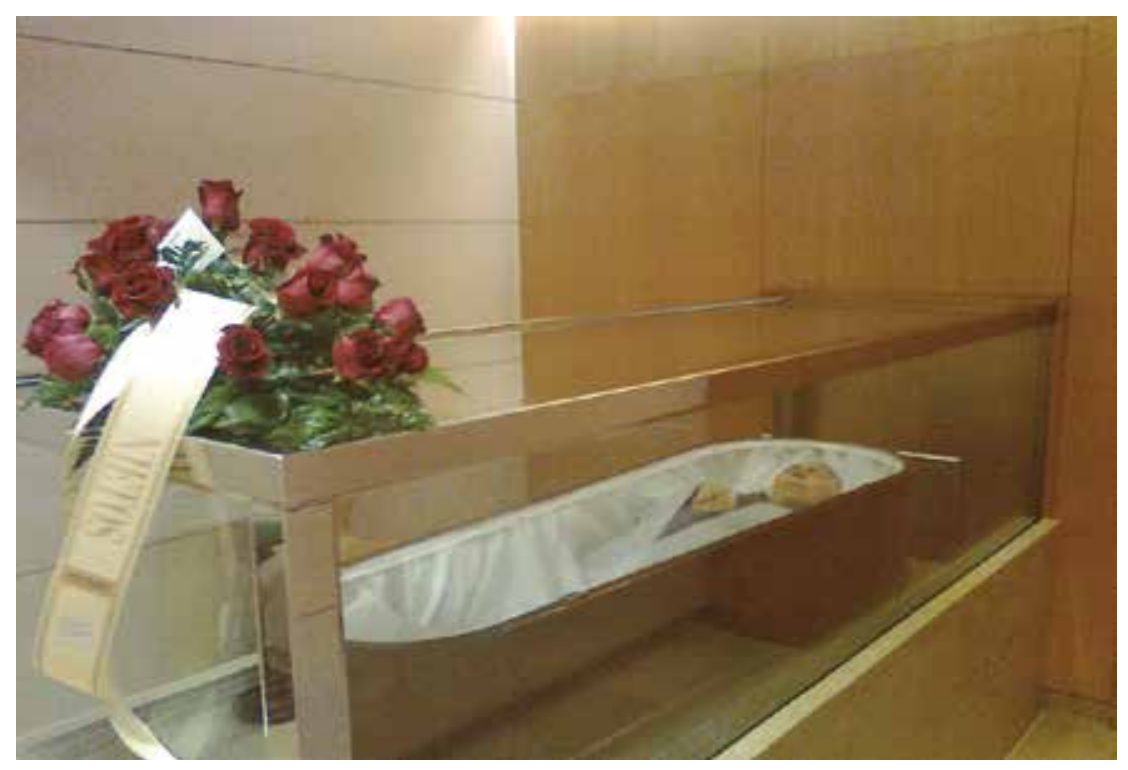

Presentación del difunto en la sala del velatorio. Dolors García. 2012.

\section{Conclusiones}

El ritual mortuorio representa la institucionalización del paso de vivo a muerto, un cambio de estado simbolizado por tres fases - separación, margen y agregación — que, en su conjunto, enmarcan el tránsito que el finado protagoniza en su traspaso a la sociedad invisible de los muertos. Los mecanismos culturales para vehicular el tránsito imaginario de los seres queridos hacia el nuevo estatus suponen una serie de procedimientos encaminados a la gestión del cuerpo, que no solo tienen como objetivo sacralizar la pérdida, sino que, implícitamente, tratan el proceso de putrefacción. Por eso, los espacios de la muerte reflejan la ambivalencia fundamental del cuerpo en tanto que es la persona a 
quien se recuerda y, a la vez, el cadáver y su inmanente descomposición. La disposición del cuerpo sin vida transcurre en un espacio concreto que, como diría Foucault (2010), equivale a un lugar «otro» o lugar real donde se aloja el imaginario, en este caso las creencias sobre el cadáver y la muerte a las que hay que atender para el funcionamiento normal de la sociedad. Debido a esto, los espacios de la muerte trabajan especialmente la simbolización, en un fuerte «como si» aún estuviera vivo, aunque todo el mundo sepa que, en efecto, el muerto está muerto y todo es un dispositivo técnico de apoyo. La asistencia al cadáver sucede en el tanatorio, donde se encuentra habilitado un espacio que cumple una función fundamental en la celebración de la muerte, ya que facilita un lugar reservado para su preparación —el backstage — y otro para su presentación ante quienes han venido a despedirlo - el front-, necesarios ambos para el buen funcionamiento de toda escenificación. $\mathrm{Su}$ última actuación es aquella mediante la cual los familiares y los amigos se reúnen en su presencia para despedirlo. Ante él, las manifestaciones de tristeza derivadas del duelo y las muestras de respeto y de solidaridad contribuyen a crear un ambiente de homenaje y solemnidad alrededor de nuestro ser querido. Para que el muerto pase a ser antepasado y para tenerlo presente en nuestra memoria, el cuidado de la última imagen, la que evoca lo que fue y no su inminente putrefacción, es un factor clave para la instalación efectiva del recuerdo.

En la representación habitual de la muerte, descansar en paz requiere una presentación del finado como si estuviese inmerso en un dulce sueño, tendido y sin mostrar el aspecto traumático de la muerte. De ahí que las técnicas para embellecer el cadáver sean algunas de las actividades que se desarrollan en el ritual de separación. Devolverles provisionalmente el aspecto de vida significa dar belleza ceremonial a los muertos, lo que no solo se consigue mediante los actos performativos de homenaje para con el difunto, sino también mediante la aplicación de la tanatopraxia y la tanatoestetica, para su higiene y conservación. Estas técnicas de reconstitución temporal del cadáver engloban las tareas de limpieza e higiene del cuerpo, taponamiento de los orificios, vestimenta, peinado y maquillaje. Se trata de atenciones prestadas por los tanatopractores del tanatorio, utilizando diversos productos y herramientas, de ahí que se haga referencia al trabajo de disposición del cuerpo sin vida como si se llevase a cabo un «arte restaurativo» (Turner y Edgley, 2005, p. 123). Las atenciones y el cuidado minucioso del finado, tan usuales en el contexto del funeral home de EE. UU., como manicura, pedicura, depilación, vestido hecho a medida y utilización de peluca, llevan al máximo nivel la idea fuerza de embellecer para salvaguardar las impresiones que suscita el cuerpo presente. 
El cadáver es el soporte material sobre el cual se ejerce la actividad colectiva en torno a la muerte. Los rituales celebrados en su honor transforman los restos humanos insignificantes en un cuerpo significante: el del ser querido a quien simbólicamente se desea ayudar en su traspaso a la comunidad de los muertos y a quien se quiere recordar en su imagen más digna, la que ayudará a soportar mejor el duelo. Por el contrario, liberarse del cuerpo sin practicar ningún tipo de intervención y sin dedicarle una atención ritual mínima es «una manera inhumana, aberrante y violenta de tratar al difunto» (Favole, 2003, p. 32). Comentarios como «iQué expresión tan apacible!» o «Está más guapo que nunca» demuestran que la belleza y la juventud reinan para siempre. Entonces cerramos el féretro, conservando el recuerdo de esa belleza: la inmortalidad de la imagen.

Aun así, la profesionalización del ritual con las técnicas de tanatopraxia y tanatoestética ha hecho que algunos autores hablen de la decadencia progresiva del ritual funerario (Ariès, 1982; Allué, 1989; Huntington, 1979; Thomas, 1991). El progreso de la técnica, los aumentos de la cremación, los cambios en las creencias sobre la muerte y el más allá, la reducción del grupo familiar, la hospitalización del acto de morir, la posibilidad de poner el cuerpo sin vida en manos de la ciencia médica, etcétera, han cambiado el ambiente funerario actual y han permitido la aparición de «formas distintas y menos elaboradas, que evidencian que los rituales funerarios funcionen como un símbolo para rendir culto a la vida, más que a la muerte» (Torres, 2006, p. 110). La inoperancia del proceso, la no movilización social a favor del cambio que obedece a una cultura que aparta la muerte de la esfera social, el favorecer la política del olvido por la profesionalización y desacralización del ritual, la reglamentación estricta de la policía sanitaria mortuoria, etcétera, son fenómenos a los cuales se atribuye restar eficacia funcional al ritual y dejar de ser «una manifestación pública del adiós y una lenta digestión compartida del dolor por la pérdida, para convertirse en un acto de trámite» (Allué, 1998, p. 79). El largo velatorio del cadáver y la cantidad de dinero a pagar hace que se sientan impropios e inútiles, incluso por parecer que no son las liturgias que el ser querido se merece, por ser considerados una caricatura y una burla. Por todo ello, algunos círculos concretos muy secularizados renuncian a la ceremonia del cuerpo presente y al entierro, abandonan los funerales tradicionales y las manifestaciones externas de duelo y abren nuevas perspectivas de abordaje. 


\section{Referencias.}

Allué, M., 1998. La ritualización de la pérdida. Anuario de Psicología, 29(4), p. 67-82.

Ariès, P.H., 1982. La muerte en Occidente. Barcelona: Argos Vergara.

Bradbury, M., 1999. Representations of Death: A Social Psychological Perspective.

Abingdon: Psychology Press.

Chihu, A. y López, A., 2000. El enfoque dramatúrgico en Erving Goffman. Polis 2000. Anuario de Sociología, pp. 239-255.

Douglas, M., 1991. Pureza y peligro: un análisis de los conceptos de contaminación y tabú. Madrid: Siglo XXI.

Favole, A., 2003. Resti di umanità. Vita sociale del corpo dopo la morte. Roma-Bari: Laterza.

Foucault, M., 2010. El cuerpo utópico: las heterotopias. Buenos Aires: Nueva visión.

Goffman, E., 2009. La presentación de la persona en la vida cotidiana. 2a ed. Madrid: Amorrortu.

Hertz, R., 1990. La muerte y la mano derecha. Madrid: Alianza Editorial.

Panizo, L., 2002. Cuerpos desaparecidos. La ubicación ritual de la muerte desatendida. En: C. Hidalgo, ed. 2002. Etnografías de la Muerte. Rituales, desapariciones, VIH/SIDA y resignificación de la vida. Buenos Aires: Ediciones Ciccus.

Radcliffe-Brown, A. R., 1986. Estructura y función en la sociedad primitiva.

Barcelona: Planeta De Agostini.

Thomas, L.-V., 1983. Antropología de la muerte. México, D.F.: Fondo de Cultura Económica.

Thomas, L.-V., 1989. El cadáver. De la biología a la antropología.

México, D.F.: Fondo de Cultura Económica.

Thomas, L.-V., 1991. La muerte: una lectura cultural. Barcelona: Paidós.

Torres, D., 2006. Los rituales funerarios como estrategias simbólicas que regulan las relaciones entre las personas y las culturas. Sapiens, 002(4), pp.107-118.

Turner, R. y Edgley, C., 2005. Life as a Theater: A Dramaturgical Sourcebook.

Nueva York: Aldine Transaction. 
Van Gennep, A., 2008. Los ritos de paso. Madrid: Alianza.

Este estudio es una muestra de la investigación llevada a término como trabajo final del máster de Antropología y Etnografía de la Universidad de Barcelona, bajo la supervisión del tutor Dr. Manuel Delgado Ruiz.

\section{Dolors García Torra}

Diplomada en Enfermería por la Escuela de Enfermería Blanquerna, Universidad Ramon Llull (1999). Licenciada en Antropología Social y Cultural por la Universidad de Barcelona (2007) y Máster en Antropología y Etnografía (2012), Universidad de Barcelona. Actualmente estoy inscrita en el programa doctoral en la misma universidad y mi investigación versa sobre las diferentes formas de apropiación social del cementerio nuevo de Igualada, premio FAD de arquitectura otorgado al trabajo de los arquitectos Enric Miralles y Carmen Pinós en 1992.

Instituciones:

Facultad de Geografía e Historia. Calle de Montalegre, 6, 08001 Barcelona

Centro donde se llevó a cabo el trabajo de campo:

Funeraria Anoia. Carretera de Vilanova, 44, 08700 Barcelona. 